\title{
Homeodomain-interacting protein kinase 2 (HIPK2): a promising target for anti-cancer therapies
}

\author{
Yuanyuan Feng ${ }^{1, *}$, Lihong Zhou ${ }^{1, *}$, Xiaoting Sun ${ }^{1}$ and Qi Li ${ }^{1}$ \\ ${ }^{1}$ Department of Medical Oncology, Shuguang Hospital, Shanghai University of Traditional Chinese Medicine, Shanghai, China \\ * These authors have contributed in equal measure as the first author
}

Correspondence to: Qi Li, email: Izwf@hotmail.com

Keywords: HIPK2; cancer; p53; apoptosis; angiogenesis

Received: September 02, $2016 \quad$ Accepted: January 04, $2017 \quad$ Published: January 18, 2017

\section{ABSTRACT}

The HIPK2 (serine/threonine homeodomain-interacting protein kinase 2 ) is a "caretaker" gene, its inactivation increases tumorigenicity while its activation inhibits tumor growth. This report reviews the anti-tumorigenic mechanisms of HIPK2, which include promotion of apoptosis, inhibition of angiogenesis in hypoxia, prevention of tumor invasion/metastasis and attenuation of multidrug resistance in cancer. Additionally, we summarize conditions or factors that may increase HIPK2 activity.

\section{INTRODUCTION}

Since being discovered in 1998 by Kim et al. using a yeast two-hybrid screen designed to characterize novel molecules that bind to homeoproteins, the homeodomaininteracting protein kinases (HIPKs), have been proven to be a tumor suppressor and one of the highly conserved factors regulating signaling and gene expressions. They control a wide spectrum of biological functions such as DNA damage response, apoptosis, hypoxia, cell proliferation and invasion $[1,2,3,4]$.

The HIPK family members 1 to 3 are structurally similar, with HIPK4 being remotely related to them. HIPK 1 to 3 were originally characterized as molecules that interact with, homeobox transcription factors NKx1.2. Approximately $90 \%$ of the amino acid sequences that make up their kinase domains are conserved across HIPK1-3. Additionally, the architecture of their noncatalytic regions is also conserved [5, 6]. HIPK2 inhibits tumor growth through multiple mechanisms: promoting apoptosis, inhibiting angiogenesis, tumor invasion and metastasis by regulating various genes and signaling molecules such as p53 [7], JNK [8], Wnt [9], and VEGF [10]. Conditions and factors that lead to HIPK2 activation, such as ionizing radiation [11], ultraviolet light [12] and zinc [13], attenuate caspase-mediated cleavage of auto-inhibitory domain and ubiquitination, resulting in simulation, acetylation as well as phosphorylation of the protein $[2,14]$. Scientific consensus suggests, HIPK2 is a "caretaker" gene: its inactivation increases tumorigenicity [15] and its activation inhibits tumor growth [6]. In this review, we discuss the function of HIPK2 and factors that may increase HIPK2 activity in order to expand current understanding of its anti-tumor effects.

\section{HIPK2 STRUCTURE}

HIPK2, a nuclear body localized 1189-aminoacid protein, belongs to the DYRK serine/threonine homeodomain-interacting kinase family [16]. HIPK2 contains an N-terminal kinase domain, a SUMO (small ubiquitin-related modifier) attachment site [17], a proteinprotein interaction region, a homeobox-interacting domain (HID), a speckle-retention signal (SRS) domain [16, 18] (required for the subcellular localization of HIPK2 to nuclear bodies), and a C-terminus abundant in repeats of serines, glutamines and alanines (SQA region, also called tyrosine/histidine (YH)-rich region) $[16,18]$. The C-terminus also contains an auto-inhibitory domain (AID) with a K1182 ubiquitination site which is ubiquitylated by p53 inhibitor mouse double minute 2 (MDM2) [20] (Figure 1). When cleaved by caspases on D916 and D977, full activation of HIPK2 ensues [19, 21].

\section{FUNCTIONS OF HIPK2}

\section{HIPK2 promotes cancer cell apoptosis}

It has been reported that HIPK2 is a tumorinhibiting factor and DNA damage monitoring kinase 
by promoting apoptosis through targeting p53 and its family members, p73 and p63 [22], anti-apoptotic transrepressor C-terminal binding protein (CtBP) [23, 24], MDM2 [25], Caspase-dependent processing [14] and the scaffold protein Axin [26]. In addition, factors associated with the pro-apoptotic effects of HIPK2, such as high mobility group AT-hook 1 (HMGA1) and Non-receptor tyrosine kinase (Src) overexpression, maintain the nuclear localization of HIPK2 and cellular sensitivity to apoptosis [26-28]. Human Papillomavirus E6 Proteins (HPV23 E6) inhibits HIPK2-mediated phosphorylation of p53 at Ser46 by disrupting HIPK2/p53 complex [29]. These lines of evidence demonstrate that the promoting role of HIPK2 in apoptosis involves various signaling pathways.

The key step for HIPK2 to promote apoptosis is phosphorylating and activating p53 at serine $46[7,31$, 32]. p53 is a widely studied transcription factor that tightly regulates cellular responses to stress signals, via modulating expression of certain genes that impact growth arrest, senescence, apoptosis and DNA repair [33]. It can be inactivated by genetic mutations or deregulated by regulatory proteins [34] and other mechanisms, such as the up-regulation of its E3 ubiquitin ligase MDM2 [33]. HIPK2 is also among the kinases, such as DNA damage checkpoint kinases Ataxia telangiectasia mutated (ATM), ATM and Rad3-related (ATR) as well as their downstream checkpoint effector kinases 1 (Chk1), checkpoint effector kinases 2(Chk2), that regulate p53 protein stability, activity and target gene specificity, [34, 35]. HIPK2 induces p53-dependent apoptosis through phosphorylating p53 at Ser46 and acetylating p53 at Lys382 [12, 36] (Figure 2). MDM2-dependent HIPK2 degradation blocks p53 activation to promote cell survival. Apoptosis can be initiated by repressing HIPK2 degradation, strongly suggesting that HIPK2 is a potential target for cancer therapy [37, 38]. Upon sensing DNA damage, HIPK2 interacts with itself and undergoes autophosphorylation at Thr880/Ser882 [39]. The prolyl isomerase (Pin1) serves as a necessary auxiliary factor for stabilizing HIPK2 following DNA damage, hence essential for apoptosis induction [39, 40]. Axin mediates interaction between Death domain- associated protein 6 (Daxx) and p53. When DNA damage occurs due to UV irradiation, the nucleustranslocated Axin interacts with Daxx and two forms of p53 (one bound with Axin, and the other with HIPK2). In the Axin-Daxx-p53-HIPK2 complex, activated HIPK2 induces phosphorylation of p53 at Ser46, which is further enhanced by Axin and Daxx. Axin-activated p53 induces apoptosis through transactivating target genes such as p53 up-regulated modulator of apoptosis (PUMA) [41]. Of note, promoting cancer cell apoptosis is the main rationale behind the cancer treatment strategies that utilize ionizing radiation and chemotherapeutic drugs. HIPK2 interacts with the C-terminus of p53 to phosphorylate the NH2-terminal Ser46 to initiate the p53-dependent transactivation of pro-apoptotic genes, such as p53AIP1 [42], p21Wafl [43], Noxa [44], Bax [45] and Puma [46], leading to cell death $[7,12]$. p53 allows caspase-mediated cleavage of HIPK2 at D916/D977 (Figure 1). The resulting C-terminal truncated HIPK2 demonstrates an elevated p53 activity and cell apoptosis [19]. HIPK2 can also induce apoptosis through caspase-6 activation [47]. Intriguingly, more and more evidence supports the novel notion of HIPK2 being a key regulator of the NF-kB signaling pathway, which often promotes abnormal expression of tumor-associated genes that inhibits cell apoptosis and increases angiogenesis and tumor metastasis, thereby directly promoting the incidence and development of malignant tumors [48].

\section{HIPK2 decreases angiogenesis in a hypoxic environment}

Strong evidence demonstrates that HIPK2 plays a role in hypoxic response via being a co-suppressor of

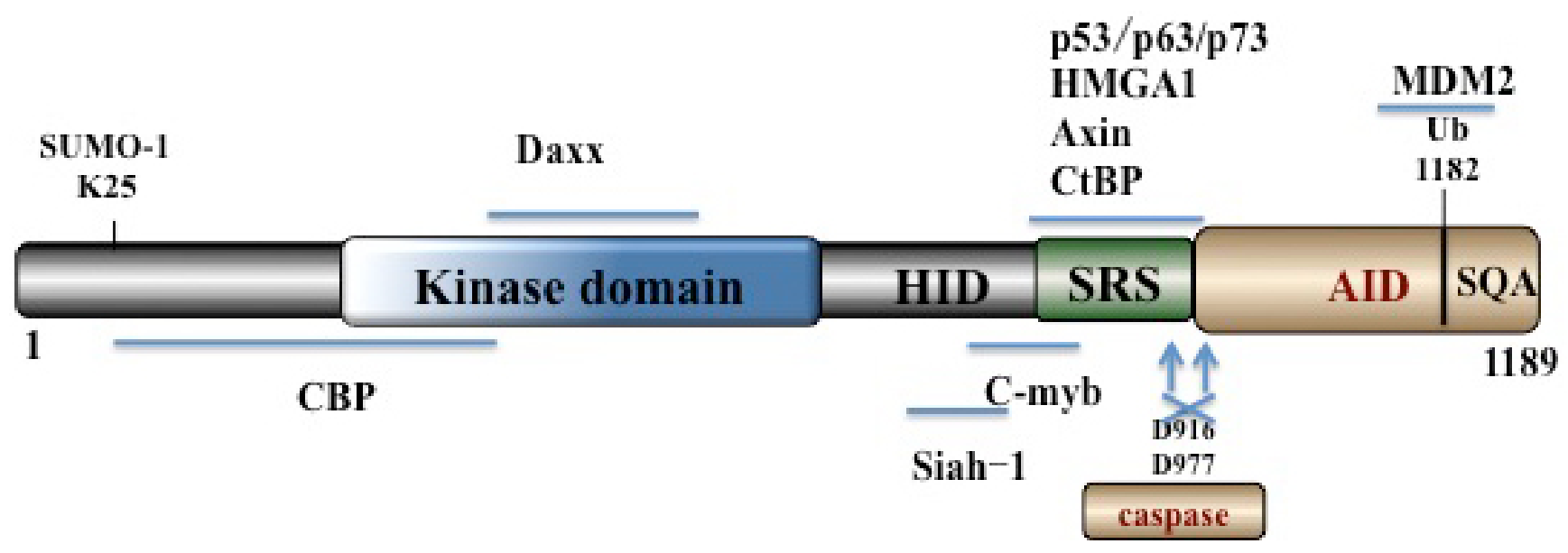

Figure 1: Schematic summary of HIPK2 domain structure. It contains an N-terminal kinase domain, sumoylation site, kinase domain, HID, SRS and a C-terminal auto-inhibitory domain (AID) with the K1182 ubiquitination site. 
hypoxia inducible factor $1 \alpha$ (HIF-1 $\alpha$ ), a major tumorigenic factor transactivating angiogenesis and invasion related genes [34].

Under hypoxia, repression of prolyl hydroxylation leads to the steady accumulation of HIF- $1 \alpha$. In turn, HIF$1 \alpha$ and HIF-1 $\beta$ dimerize to become the functional HIF1 complex to increase the expression levels of cancerpromoting genes [49]. Thus, inhibiting HIF-1 $\alpha$ activity may help enhance efficacy of conventional cancer therapy [50]. Hypoxia may down-regulate HIPK2 by inducing the p53 target MDM2 leading to both suppression of HIF-1 $\alpha$ activity and p53-mediated apoptosis [51]. Nardinocchi et al. [13] used inhibition of HIF-1 $\alpha$ by small inhibitory RNA (siRNA) to demonstrate that HIF-1 $\alpha$ up-regulation induced proteasomal degradation of HIPK2. To sum up, hypoxia-induced ubiquitin ligases such as Seven in absentia 2 (Siah2), Seven in absentia 1 (Siah1) or MDM2, induce HIPK2 degradation which effectively inhibits therapy-induced $\mathrm{p} 53$ apoptotic activity, thereby promoting cancer progression [52-55].

Under hypoxia, HIPK2 is degraded in a proteasomedependent and Siah1-dependent manner [56]. In normoxia, HIPK2 stability is maintained by a number of factors, with some HIPK2 proteins associated with Siah2. Hypoxic conditions commence marked increase in HIPK2/Siah2 association, resulting in rapid polyubiquitylation dependent proteasomal degradation of HIPK2. Under hypoxic conditions, Siah1 and Siah2 mediate the ubiquitination and proteasomal destruction of prolyl hydroxylase domain protein PHD1 and PHD3, which induces HIF- $1 \alpha$ protein stabilization and increasing expression levels of HIF-1 target genes, e.g. vascular endothelial growth factor (VEGF) [57].

There are reports that WD40 domain and suppressor of cytokine signaling (SOCS) box protein-1 (WSB-1) is not only involved in sensing DNA damage by targeting HIPK2 for degradation, but that it is also a target of HIF1 [58]. Hypoxia-induced HIPK2 degradation is reversed by WSB-1 loss. Inhibition of WSB-1 expression increases HIPK2 expression and promotes cell death in hypoxic cells [59]. In addition, HIPK2 silencing up-regulates HIF- $1 \alpha$ and HIF-1 activity, resulting in increased VEGF levels, angiogenesis, and chemo-resistance [10, 60]. HIF$1 \alpha$ and VEGF up-regulation in HUVEC cells correlate with increased vascularity of in vivo xenografts and tube formation in vitro [10]. Increased vascularity following

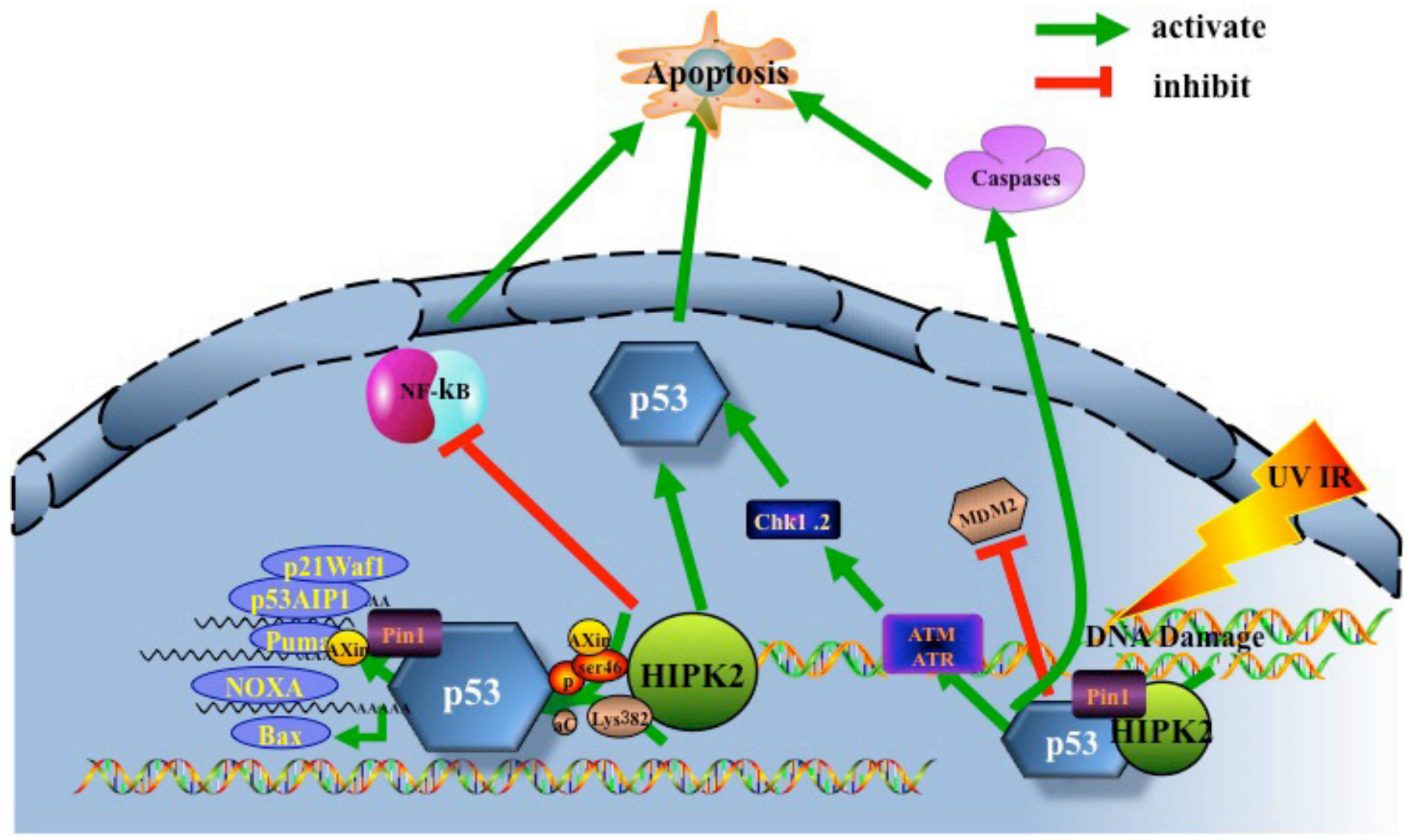

Figure 2: HIPK2/p53 induce apoptosis. UV, IR-induced DNA damage facilitates activation of the DNA damage-activated protein kinases ATM and ATR. ATR and ATM in turn phosphorylate/activate downstream checkpoint kinases Chk1, Chk2, and tumour suppressor p53. Furthermore, ATM and ATR mediate HIPK2 activation by facilitating its stabilization through phosphorylation of the HIPK2 ubiquitin ligase. HIPK2 contributes to p53 apoptotic activation by inducing Ser46 phosphorylation, lysine 382 (Lys382) acetylation and Axin. Pin1 can induce HIPK2 stabilization and p53 Ser46 phosphorylation, essential for induction of apoptosis. HIPK2-mediated phosphorylation of p53 at Ser46 potentiates the activation of pro-apoptotic p53 target genes such as p53AIP1, p21Waf1, Noxa, Bax and Puma, resulting in cell death. In addition, HIPK2 can induce apoptosis through direct caspase activation and NF-kB pathway inactivation. 
VEGF up-regulation directs tumor progression [61]. In brief, HIPK2 can inhibit angiogenesis by regulating VEGF, siah-1, siah-2, WSB-1 and HIF-1 in hypoxia.

\section{HIPK2 suppresses tumor invasion and metastasis}

Tumor invasion and metastasis are complicated processes with multiple steps. Previous studies have confirmed that HIPK2 mediates tumor invasion and metastasis [9], alas with undefined mechanisms. HIPK2 activation induces Ser422 phosphorylation and degradation of CtBP to repress tumor metastasis [24]. Increasing body of evidence indicates that $\mathrm{CtBP}$ is a key promoter of carcinogenesis, especially in cancer metastasis [62]. CtBP participates in the down-regulation of E-cadherin gene, a marker of epithelial-mesenchymal transition (EMT) that contributes to cancer metastasis. Therefore, expression of CtBP is critically related to the malignant transformation of a number of cancers [63-65].

Studies have indicated that HIPK2 is involved in tumor invasion by inhibiting various signaling pathways [9]. Firstly, data have indicated that the well-studied wingless/int (Wnt) signaling pathway has a definite role in tumor invasion. Activation of this pathway can alter the expression of cell adhesion molecules, proteases and angiogenesis factors to promote cell invasion [66-68].
Secondly, knockdown of HIPK2 stabilizes $\beta$-catenin, increases nuclear localization of $\beta$-catenin, resulting in enhanced expression levels of Wnt target genes and cell proliferation in vivo and in vitro. HIPK2 down-regulates the $c-m y b$ proto-oncogene product by inhibiting the Wnt/ $\beta$-catenin signaling pathway [69]. c-Myb is downstream effector of $\mathrm{Wnt} / \beta$-catenin pathway, controlling a variety of developmental steps, inhibition of proliferation and invasion [70, 71]. Studies also have showed that that c-Myb protein is phosphorylated and degraded by Wnt1 via a pathway involving TGF- $\beta$-activated kinase (TAK1), HIPK2 and Nemo-like kinase (NLK) [72]. Wnt1 signaling activates the mitogen-activated protein (MAP), NLK and HIPK2. NLK induces phosphorylation of c-Myb at different sites by interacting with c-Myb and HIPK2, resulting in the ubiquitination and proteasome-dependent degradation of c-Myb. c-Myb regulates proliferation, differentiation and apoptosis via affecting transcription of target genes [73]. Meanwhile, Tan et al. showed that HIPK2 inhibition increased EMT and cell invasion, which was probably mediated by Wnt signaling [9].

Thirdly, depletion of HIPK2 activates $\beta 4$ transcription, leading to a significantly higher level of phosphorylation of $\beta 4$-dependent mitogen-activated protein kinase (MAPK) and Akt, and consequent promotion of anchorage-independent growth and invasion [74]. HIPK2 knockdown also leads to HIF-1-mediated

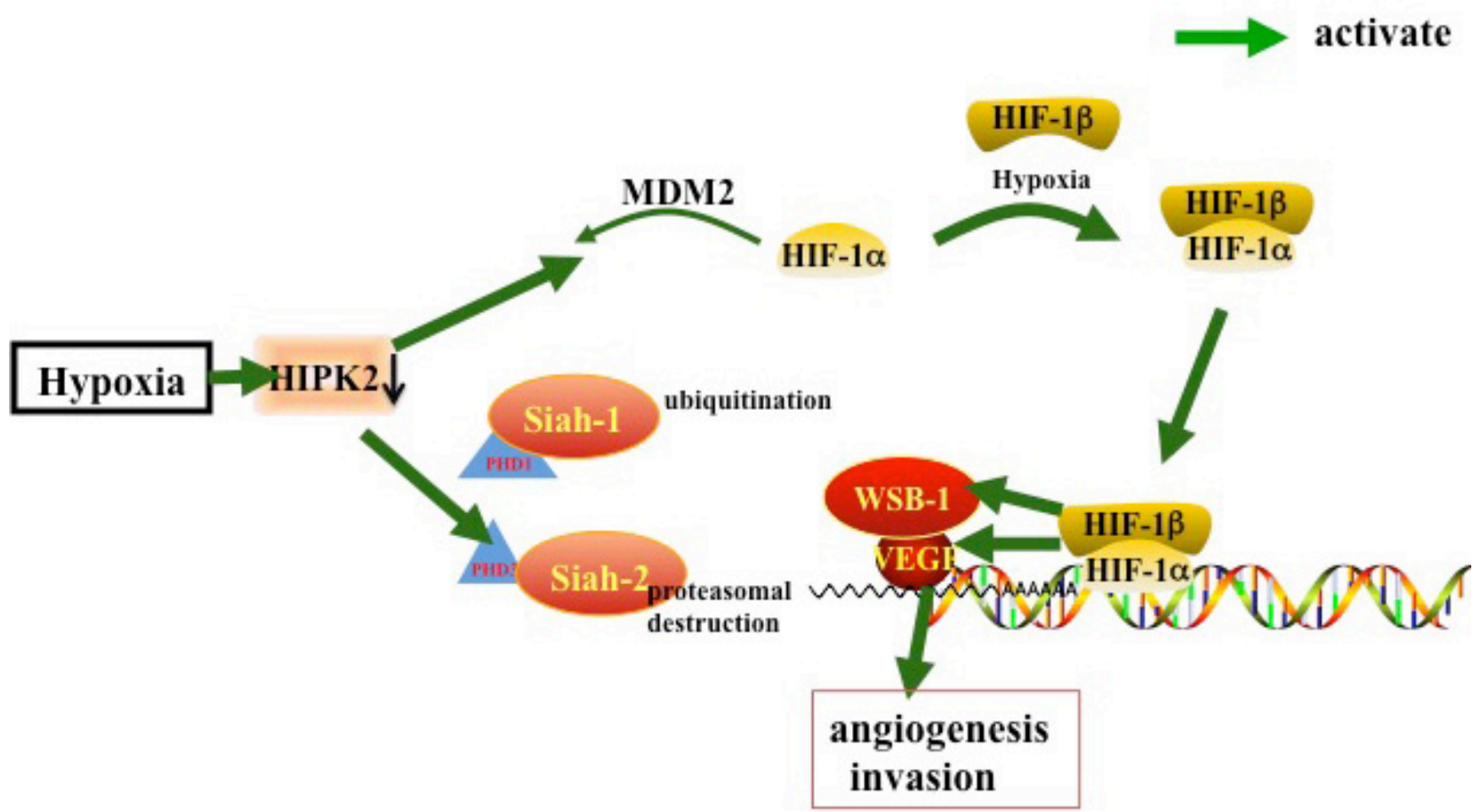

Figure 3: HIPK2 inhibits angiogenesis by regulating siah-1, siah-2, WSB-1, HIF-1 and VEGF in a hypoxic environment. In hypoxia, HIF-1 $\alpha$ dimerizes with HIF-1 $\beta$ to form the active HIF-1 complex, the PHD1/PHD3 mediated ubiquitination and proteasomal destruction of ubiquitin ligases Siah1 and Siah2 results in HIF-1 $\alpha$ stabilization and activation of HIF-1 targeting genes such as VEGF. Hypoxia down-regulate HIPK2 to activate this pathway. 
cyclooxygenase-2 (COX-2) up-regulation, which has been found to promote invasion in many types of cancer $[75,76,77]$. COX-2 expression is highly expressed in response to inflammatory mediators, growth factors, and oncogene activation, suggesting its association with cancer invasion and metastasis [78]. But whether HIPK2 directly down-regulates COX-2 to inhibit invasion and metastasis remains to be experimentally elucidated. Nodale et al. [79] found HIPK2-mediated vimentin downregulation led to suppression of cancer cell invasion. In addition, evidence revealed that HIPK2 participated in the transforming growth factor beta (TGF- $\beta$ )-JNK signaling dependent up-regulation of invasion and metastasis. RNA interference mediated HIPK 2 knockdown inhibits TGF- $\beta$ -induced JNK activation [8], and HIPK2 effect on JNK is modulated through dynamic SUMO-1 modification [80]. JNK signaling pathways are strongly associated with tumor progression and metastasis [81, 82]. Therefore, HIPK2 may decrease tumor invasion and metastasis through its regulation of JNK signaling pathways.
HIPK2 attenuates multidrug resistance (MDR) in cancer

Multidrug resistance (MDR) represents one of a variety of mechanisms that cancer cells use to evade the cytotoxic effects of various anti-cancer drugs, thus decreases the efficacy of cancer therapeutics [83]. Inhibition of HIPK2 attenuates the adriamycin-induced apoptosis by decreasing pSer46-p53 levels, whilst HIPK2 overexpression induces apoptosis in chemoresistant cancer cells, along with induction of p53 Ser46-target gene AIP1 [84]. This conceptual result led to studies testing HIPK2 as a therapeutic target of gene therapy for chemoresistant ovarian cancer with wtp53 [12, 20, 84]. Lin et al. [85] found that HIPK2/Wip1 signaling might be a novel mechanism controlling chemoresistance. In detail, they confirmed that overexpression of HIPK2 sensitized chemoresistant cancer cells to cisplatin by inhibiting Wip1 expression. Hypoxia helps cancer cells to resist chemotherapy, whereas HIPK2 mediated repression of HIF-1 $\alpha$ activity confers sensitization of chemoresistant cells with drug induced apoptosis [60]. Emerging data

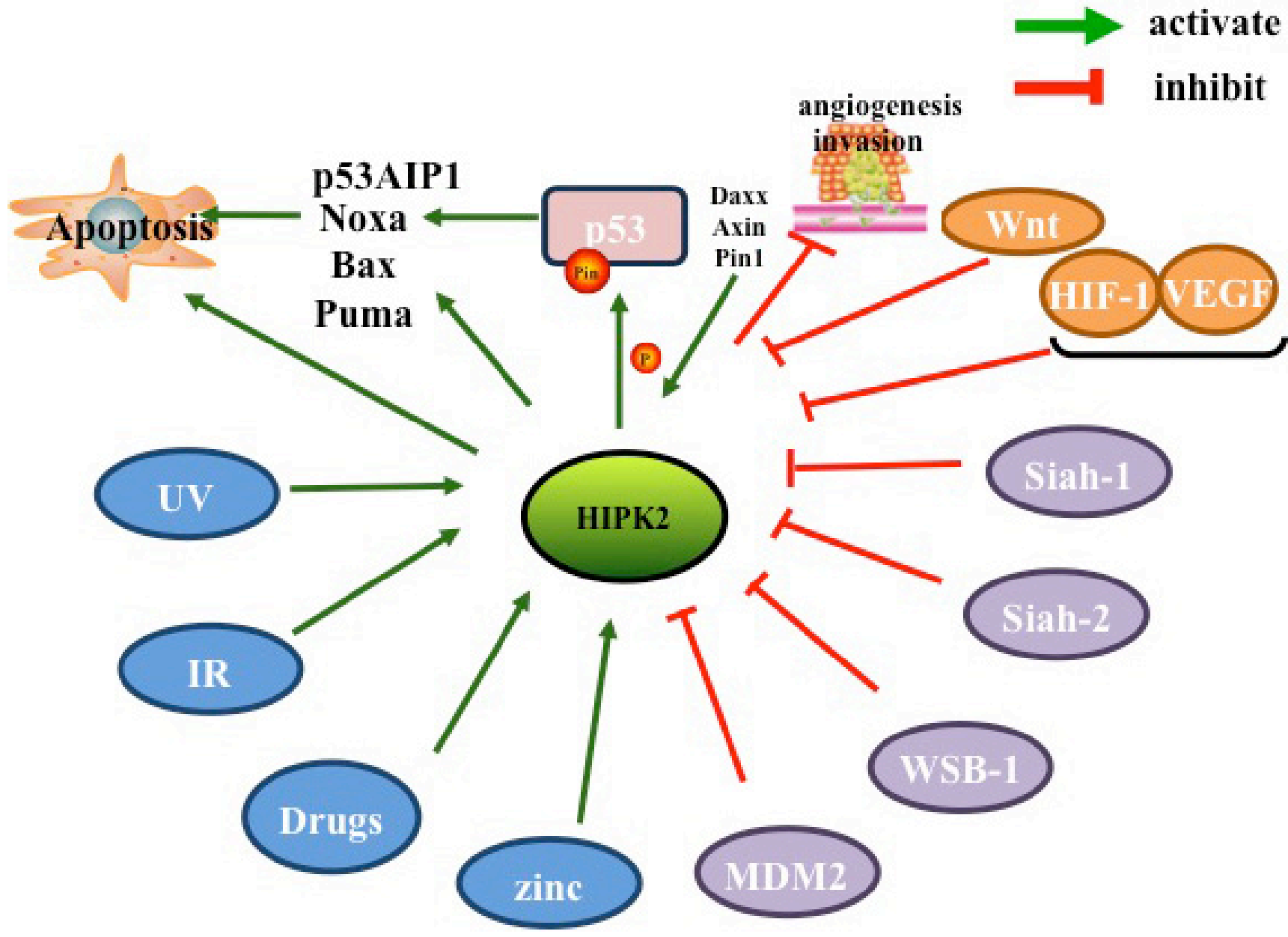

Figure 4: Factors inhibiting and promoting HIPK2 . 
also indicate that HIPK2 silencing by siRNA impairs p53 tumor suppressor function, induces chemoresistance, and increases in vivo tumor growth [86]. HIPK2 inactivation unleashes signaling pathways that result in p53 loss-offunction and chemoresistance $[12,34]$. Other observations showed that HIPK2 knockdown induced resistance to various anti-cancer drugs even by targeting $\triangle \mathrm{Np} 63 \alpha$ in p53-null cells [87]. These results suggest that HIPK2 can restore chemo sensitivity and inhibit chemo resistance.

\section{Conditions/factors that enhance HIPK2 activity}

HIPK2 can be activated by numerous DNA damaging factors, including ultraviolet light (UV light), ionizing radiation (IR), genotoxic chemo-therapeutics [88], zinc in a hypoxic environment [13] and herbs used in traditional Chinese Medicine [89].

\section{Ionizing radiation (IR)}

Studies have showed that IR induces the accumulation and activation of HIPK2.

IR-induced up-regulation of HIPK2 correlates with phosphorylation of p53 at Ser46, which is inhibited by RNAi mediated HIPK2 silencing. Interestingly, the DNA damage checkpoint ataxia telangiectasia mutated (ATM) kinase mediates IR induced HIPK2 activation [11] [90].

\section{Ultraviolet light}

Upon sensing UV damage, HIPK2 is activated and causes Ser46 phosphorylates of p53, which next facilitates its acetylation at lysine 382, resulting in p53-dependent apoptosis [12]. After exposure to UV or cisplatin, HIPK2 and JNK1, provoke phosphorylation of CtBP at Ser422, to initiate apoptosis [91].

\section{Chemotherapy drugs}

HIPK2 is activated by various anti-cancer drugs, including cisplatin (CDDP), adriamycin (ADR) and roscovitin, to form HIPK2/p53Ser46 apoptotic signaling pathway. Therefore, HIPK2 is the key factor of p53 activity in response to chemotherapeutic drugs [92]. In chemoresistance, deregulation of HIPK2/p53 Ser46 signaling occurs. For conceptual novelty, exogenous HIPK2 should offer a valuable and promising new treatment option to circumvent inhibition of apoptosis for women with chemo-resistant ovarian cancer [84].

\section{Zinc}

In addition to DNA damaging agents, HIPK2 can be activated by zinc in hypoxia and in chemoresistance. Zinc restored protein levels of HIPK2 and the chemo-sensitivity in cancer cells [13]. Zinc up-regulated HIPK2 to inhibit COX-2 level, leading to reduced cancer growth [75]. Some study even showed that zinc could reactivate HIPK2 resulting in HIF-1 pathway suppression, thereby restoring p53 apoptotic activity [93]. p53 protein misfolding in HIPK2 knockdown context was reverted by zinc supplementation [94]. Therefore, zinc treatment should be used in combination with other anticancer therapeutics to restore the HIPK2/p53 apoptotic signaling pathway.

\section{Herbs used in traditional chinese medicine}

The reason Traditional Chinese medicine comes to our attention in this review is because of a study revealing inhibition of HIF-1 and S100A4 by saponin extracts of ginsenoside (Ginsen) and Gynostemma, as well as coix polysaccharides, resulting in the suppression of cancer cell migration and invasion [95]. Verbascoside (VB), extracted from a Traditional Chinese medical plant genus, effectively activates HIPK2/p53 signaling pathway in human colorectal cancer $(\mathrm{CRC})$, resulting in increased CRC cell apoptosis [89].

\section{CONCLUSIONS}

HIPK2 is a multi-functional signaling molecule and a tumor suppressor that mediates growth, regulation and apoptotic cellular responses. HIPK2 induces cell death by activating p53-dependent [7, 22, 31, 32] and independent pathways (including the JNK signaling pathway) [8, 80], to promote tumor cell apoptosis. In a hypoxic environment, HIPK2 down-regulates the activity of HIF1 [34], Siah1 [56], Siah2 [3], VEGF [57] and WBS-1 [59] to inhibit tumor angiogenesis [50]. Additionally, several studies have shown that HIPK2 can also decrease tumor cell invasion and metastasis by Wnt/ $\beta$-catenin [69], CTBP [24], JNK [8, 80-82] and COX-2 signaling pathways [78]. HIPK2 can adjust MDR to increases sensitivity of cells to chemotherapy drugs $[12,20,84]$. HIPK2 can also be activated by DNA damage (i.e. ionizing radiation, UV light) [88], anti-tumor drugs (i.e. cisplatin, adriamycin, roscovitine) [92], zinc in a hypoxic environment [13], and Traditional Chinese medicine [89]. In summary, HIPK2 inhibits cancer cell tumorigenesis, and promotes proapoptotic gene expression. HIPK2 can serve as a novel biomarker in tumors as well as a potential target for anticancer therapies. 


\section{ACKNOWLEDGMENTS}

This study was supported by the Key Projects of International cooperation for National Natural Science Foundation of China (No. 81520108031), the National Natural Science Foundation of China (No. 81303103, No. 81303106, No. 81573805, No. 81573749, No.81673784), the Three-year Action Plan on Development of Traditional Chinese Medicine of Shanghai (No.ZY3-CCCX-3-3012), the Program of Shanghai Municipal Technology and Education Commission(No. 16401970500)No $.16401930700)$

\section{CONFLICTS OF INTERESTS} interests.

The authors declare that they have no competing

\section{Authors' contributions}

Conceived and designed the review: QL and YYF. Consulted and Analyzed the literature: XTS. Wrote the paper: YYF and LHZ.

\section{REFERENCES}

1. Kim YH, Choi CY, Lee SJ, Conti MA, Kim Y. Homeodomain-interacting protein kinases, a novel family of co-repressors for homeodomain transcription factors. J Biol Chem. 1998;273:25875-25879.

2. Saul VV, Schmitz ML. Posttranslational modifications regulate HIPK2, a driver of proliferative diseases. J Mol Med (Berl). 2013;91:1051-1058.

3. Calzado MA, de la Vega L, Moller A, Bowtell DD, Schmitz ML. An inducible autoregulatory loop between HIPK2 and Siah2 at the apex of the hypoxic response. Nat Cell Biol. 2009; 11:85-91.

4. Hofmann TG, Glas C, Bitomsky N. HIPK2: A tumour suppressor that controls DNA damage-induced cell fate and cytokinesis. Bioessays. 2013;35:55-64.

5. Rinaldo C, Prodosmo A, Siepi F, Soddu S. HIPK2: a multitalented partner for transcription factors in DNA damage response and development. Biochem Cell Biol .2007;85:411-418.

6. Calzado MA, Renner F, Roscic A, Schmitz ML. HIPK2: a versatile switchboard regulating the transcription machinery and cell death. Cell Cycle. 2007;6:139-143.

7. D’Orazi G, Cecchinelli B, Bruno T, Manni I, Higashimoto Y, Saito S, Gostissa M, Coen S, Marchetti A, Del Sal G, Piaggio G, Fanciulli M, Appella E, et al. Homeodomaininteracting protein kinase-2 phosphorylates p53 at Ser 46 and mediates apoptosis. Nat Cell Biol. 2002;4:11-19.

8. Hofmann TG, Stollberg N, Schmitz ML, Will H. HIPK2 regulates transforming growth factor-beta-induced c-Jun $\mathrm{NH}(2)$-terminal kinase activation and apoptosis in human hepatoma cells. Cancer Res. 2003;63:8271-8277.

9. Tan M, Gong H, Zeng Y, Tao L, Wang J, Jiang J, Xu D, Bao E, Qiu J, Liu Z. Downregulation of homeodomaininteracting protein kinase-2 contributes to bladder cancer metastasis by regulating Wnt signaling. J Cell Biochem. 2014;115:1762-1767.

10. Nardinocchi L, Puca R, Guidolin D, Belloni AS, Bossi G, Michiels C, Sacchi A, Onisto M, D’Orazi G. Transcriptional regulation of hypoxia-inducible factor 1alpha by HIPK2 suggests a novel mechanism to restrain tumor growth. Biochim Biophys Acta. 2009;1793:368-377.

11. Dauth I, Kruger J, Hofmann, TG. Homeodomain-interacting protein kinase 2 is the ionizing radiation-activated p53 serine 46 kinase and is regulated by ATM. Cancer Res. 2007;67:2274-2279.

12. Hofmann TG, Moller A, Sirma H, Zentgraf H, Taya Y, Droge W, Will H, Schmitz ML. Regulation of p53 activity by its interaction with homeodomain-interacting protein kinase-2. Nat Cell Biol. 2002;4:1-10.

13. Nardinocchi L, Puca R, D’Orazi G. HIF-1alpha antagonizes p53-mediated apoptosis by triggering HIPK2 degradation. Aging (Albany NY). 2011;3:33-43. doi: 10.18632/ aging. 100254 .

14. Sombroek D, Hofmann TG. How cells switch HIPK2 on and off. Cell Death Differ. 2009;16:187-194.

15. Valente D, Bossi G, Moncada A, Tornincasa M, Indelicato S, Piscuoglio S, Karamitopoulou ED, Bartolazzi A, Pierantoni GM, Fusco A, Soddu S, Rinaldo C. HIPK2 deficiency causes chromosomal instability by cytokinesis failure and increases tumorigenicity. Oncotarget. 2015;6:10320-10334. doi: 10.18632/oncotarget.3583.

16. Kim YH, Choi CY, Kim Y. Covalent modification of the homeodomain-interacting protein kinase 2 (HIPK2) by the ubiquitin-like protein SUMO-1. Proc Natl Acad Sci U S A. 1999;96:12350-12355.

17. Sung KS, Go YY, Ahn JH, Kim YH, Kim Y, Choi CY. Differential interactions of the homeodomain-interacting protein kinase 2 (HIPK2) by phosphorylation-dependent sumoylation. FEBS Lett. 2005;579:3001-3008.

18. Schmitz ML, Rodriguez-Gil A, Hornung J. Integration of stress signals by homeodomain interacting protein kinases. Biol Chem. 2014;395:375-386.

19. Gresko E, Roscic A, Ritterhoff S, Vichalkovski A, del Sal $\mathrm{G}$, Schmitz ML. Autoregulatory control of the p53 response by caspase-mediated processing of HIPK2. EMBO J. 2006;25:1883-1894.

20. Rinaldo C, Prodosmo A, Mancini F, Iacovelli S, Sacchi A, Moretti F, Soddu S. MDM2-regulated degradation of HIPK2 prevents p53Ser46 phosphorylation and DNA damage-induced apoptosis. Mol Cell. 2007;25:739-750.

21. Bitomsky N, Hofmann TG. Apoptosis and autophagy: Regulation of apoptosis by DNA damage signalling - roles 
of p53, p73 and HIPK2. FEBS J. 2009;276:6074-6083.

22. Winter M, Sombroek D, Dauth I, Moehlenbrink J, Scheuermann K, Crone J, Hofmann TG. Control of HIPK2 stability by ubiquitin ligase Siah-1 and checkpoint kinases ATM and ATR. Nat Cell Biol. 2008;10:812-824.

23. Choi DW, Seo YM, Kim EA, Sung KS, Ahn JW, Park SJ, Lee SR, Choi CY. Ubiquitination and degradation of homeodomain-interacting protein kinase 2 by WD40 repeat/ SOCS box protein WSB-1. J Biol Chem. 2008;283:46824689.

24. Zhang Q, Yoshimatsu Y, Hildebrand J, Frisch SM, Goodman RH. Homeodomain interacting protein kinase 2 promotes apoptosis by downregulating the transcriptional corepressor CtBP. Cell. 2003;115:177-186.

25. Shima $Y$, Shima $T$, Chiba $T$, Irimura $T$, Pandolfi PP, Kitabayashi I. PML activates transcription by protecting HIPK2 and p300 from SCFFbx3-mediated degradation. Mol Cell Biol. 2008;28:7126-7138.

26. Pierantoni GM, Rinaldo C, Mottolese M, Di Benedetto A, Esposito F, Soddu S, Fusco A. High-mobility group A1 inhibits p53 by cytoplasmic relocalization of its proapoptotic activator HIPK2. J Clin Invest. 2007;117:693702.

27. Polonio-Vallon T, Kirkpatrick J, Krijgsveld J, Hofmann TG. Src kinase modulates the apoptotic p53 pathway by altering HIPK2 localization. Cell Cycle. 2014;13:115-125.

28. Esposito F, Tornincasa M, Chieffi P, De Martino I, Pierantoni GM, Fusco A. High-mobility group A1 proteins regulate p53-mediated transcription of Bcl-2 gene. Cancer Res. 2010;70:5379-5388.

29. Muschik D, Braspenning-Wesch I, Stockfleth E, Rosl F, Hofmann TG, Nindl I. Cutaneous HPV23 E6 prevents p53 phosphorylation through interaction with HIPK2. PLoS One. 2011;6:e27655.

30. Takekawa M, Adachi M, Nakahata A, Nakayama I, Itoh F, Tsukuda H, Taya Y, Imai K. p53-inducible wip1 phosphatase mediates a negative feedback regulation of p38 MAPK-p53 signaling in response to UV radiation. EMBO J. 2000;19:6517-6526.

31. Moller A, Sirma H, Hofmann TG, Rueffer S, Klimczak E, Droge W, Will H, Schmitz ML. PML is required for homeodomain-interacting protein kinase 2 (HIPK2)mediated p53 phosphorylation and cell cycle arrest but is dispensable for the formation of HIPK domains. Cancer Res. 2003;63:4310-4314.

32. Puca R, Nardinocchi L, Givol D, D’Orazi G. Regulation of p53 activity by HIPK2: molecular mechanisms and therapeutical implications in human cancer cells. Oncogene. 2010;29:4378-4387.

33. Brooks $\mathrm{CL}, \mathrm{Gu}$ W. p53 ubiquitination: $\mathrm{Mdm} 2$ and beyond. Mol Cell. 2006;21:307-315.

34. Nardinocchi L, Puca R, Givol D, D’Orazi G. HIPK2-a therapeutical target to be (re)activated for tumor suppression: role in p53 activation and HIF-1alpha inhibition. Cell Cycle. 2010;9:1270-1275.

35. Vousden KH, Prives C. Blinded by the Light: The Growing Complexity of p53. Cell. 2009;137:413-431.

36. Puca R, Nardinocchi L, Sacchi A, Rechavi G, Givol D, D'Orazi G. HIPK2 modulates p53 activity towards proapoptotic transcription. Mol Cancer. 2009;8:85.

37. Zhang XP, Liu F, Wang W. Interplay between Mdm2 and HIPK2 in the DNA damage response. J R Soc Interface. 2014; 11 .

38. Wu X, Bayle JH, Olson D, Levine AJ. The p53-mdm-2 autoregulatory feedback loop. Genes Dev. 1993;7:11261132.

39. Bitomsky N, Conrad E, Moritz C, Polonio-Vallon T, Sombroek D, Schultheiss K, Glas C, Greiner V, Herbel C, Mantovani F, del Sal G, Peri F, Hofmann TG. Autophosphorylation and Pin1 binding coordinate DNA damage-induced HIPK2 activation and cell death. Proc Natl Acad Sci U S A. 2013;110:E4203-4212.

40. Song JY, Ryu SH, Cho YM, Kim YS, Lee BM, Lee SW, Choi J. Wip1 suppresses apoptotic cell death through direct dephosphorylation of BAX in response to gamma-radiation. Cell Death Dis. 2013;4:e744.

41. Rui Y, Xu Z, Lin S, Li Q, Rui H, Luo W, Zhou HM, Cheung PY, Wu Z, Ye Z, Li P, Han J, Lin SC. Axin stimulates p53 functions by activation of HIPK2 kinase through multimeric complex formation. EMBO J. 2004;23:4583-4594.

42. Oda K, Arakawa H, Tanaka T, Matsuda K, Tanikawa C, Mori T, Nishimori H, Tamai K, Tokino T, Nakamura Y, Taya Y. p53AIP1, a potential mediator of p53-dependent apoptosis, and its regulation by Ser-46-phosphorylated p53. Cell. 2000;102:849-862.

43. Iacovelli S, Ciuffini L, Lazzari C, Bracaglia G, Rinaldo C, Prodosmo A, Bartolazzi A, Sacchi A, Soddu S. HIPK2 is involved in cell proliferation and its suppression promotes growth arrest independently of DNA damage. Cell Prolif. 2009;42:373-384.

44. Oda E, Ohki R, Murasawa H, Nemoto J, Shibue T, Yamashita $\mathrm{T}$, Tokino $\mathrm{T}$, Taniguchi $\mathrm{T}$, Tanaka N. Noxa, a BH3-only member of the Bcl-2 family and candidate mediator of p53-induced apoptosis. Science. 2000;288:1053-1058.

45. Hedstrom E, Issaeva N, Enge M, Selivanova G. Tumorspecific induction of apoptosis by a p53-reactivating compound. Exp Cell Res. 2009;315:451-461.

46. Fritsche MK, Metzler V, Becker K, Plettenberg C, Heiser C, Hofauer B, Knopf A. Cisplatin fails to induce puma mediated apoptosis in mucosal melanomas. Oncotarget. 2015;6:9887-9896. doi: 10.18632/oncotarget.3195.

47. Pistritto G, Puca R, Nardinocchi L, Sacchi A, D’Orazi G. HIPK2-induced p53Ser46 phosphorylation activates the KILLER/DR5-mediated caspase-8 extrinsic apoptotic pathway. Cell Death Differ. 2007;14:1837-1839.

48. Jin Y, Ratnam K, Chuang PY, Fan Y, Zhong Y, Dai Y, Mazloom AR, Chen EY, D'Agati V, Xiong H, Ross MJ, 
Chen N, Ma'ayan A, et al. A systems approach identifies HIPK2 as a key regulator of kidney fibrosis. Nat Med. 2012;18:580-588.

49. Semenza GL. Targeting HIF-1 for cancer therapy. Nat Rev Cancer. 2003;3:721-732.

50. Semenza GL. Defining the role of hypoxia-inducible factor 1 in cancer biology and therapeutics. Oncogene. 2010;29:625-634.

51. Nardinocchi L, Puca R, Sacchi A, Rechavi G, Givol D, D'Orazi G. Targeting hypoxia in cancer cells by restoring homeodomain interacting protein-kinase 2 and p53 activity and suppressing HIF-1alpha. PLoS One. 2009;4:e6819.

52. Kim CJ, Cho YG, Park CH, Jeong SW, Nam SW, Kim $\mathrm{SY}$, Lee SH, Yoo NJ, Lee JY, Park WS. Inactivating mutations of the Siah-1 gene in gastric cancer. Oncogene. 2004;23:8591-8596.

53. Wen YY, Yang ZQ, Song M, Li BL, Yao XH, Chen XL, Zhao J, Lu YY, Zhu JJ, Wang EH. The expression of SIAH1 is downregulated and associated with Bim and apoptosis in human breast cancer tissues and cells. Mol Carcinog. 2010;49:440-449.

54. Yoshibayashi H, Okabe H, Satoh S, Hida K, Kawashima K, Hamasu S, Nomura A, Hasegawa S, Ikai I, Sakai Y. SIAH1 causes growth arrest and apoptosis in hepatoma cells through beta-catenin degradation-dependent and -independent mechanisms. Oncol Rep. 2007;17:549-556.

55. Brauckhoff A, Ehemann V, Schirmacher P, Breuhahn K. [Reduced expression of the E3-ubiquitin ligase seven in absentia homologue (SIAH)-1 in human hepatocellular carcinoma]. Verh Dtsch Ges Pathol. 2007;91:269-277.

56. Moehlenbrink J, Bitomsky N, Hofmann TG. Hypoxia suppresses chemotherapeutic drug-induced p53 Serine 46 phosphorylation by triggering HIPK2 degradation. Cancer Lett. 2010;292:119-124.

57. Nakayama K, Frew IJ, Hagensen M, Skals M, Habelhah H, Bhoumik A, Kadoya T, Erdjument-Bromage H, Tempst P, Frappell PB, Bowtell DD, Ronai Z. Siah2 regulates stability of prolyl-hydroxylases, controls HIF1alpha abundance, and modulates physiological responses to hypoxia. Cell. 2004;117:941-952.

58. Moinul H, Joseph KK, Ryan MMa, Douglas JD. WSB1: from homeostasis to hypoxia. J Biomed Sci. 2016; $23: 61$.

59. Tong Y, Li QG, Xing TY, Zhang M, Zhang JJ, Xia Q. HIF1 regulates WSB-1 expression to promote hypoxia-induced chemoresistance in hepatocellular carcinoma cells. FEBS Lett. 2013;587:2530-2535.

60. Nardinocchi L, Puca R, Sacchi A, D’Orazi G. Inhibition of HIF-1 alpha activity by homeodomain-interacting protein kinase-2 correlates with sensitization of chemoresistant cells to undergo apoptosis. Mol Cancer. 2009;8:1.

61. Folkman J. Angiogenesis in cancer, vascular, rheumatoid and other disease. Nat Med. 1995;1:27-31.

62. Chinnadurai G. The transcriptional corepressor CtBP: a foe of multiple tumor suppressors. Cancer Res. 2009;69:731-
734.

63. Thomas G, Jacobs KB, Yeager M, Kraft P, Wacholder S, Orr N, Yu K, Chatterjee N, Welch R, Hutchinson A, Crenshaw A, Cancel-Tassin G, Staats BJ, et al. Multiple loci identified in a genome-wide association study of prostate cancer. Nat Genet. 2008;40:310-315.

64. Pena C, Garcia JM, Garcia V, Silva J, Dominguez G, Rodriguez R, Maximiano C, Garcia de Herreros A, Munoz A, Bonilla F. The expression levels of the transcriptional regulators p300 and $\mathrm{CtBP}$ modulate the correlations between SNAIL, ZEB1, E-cadherin and vitamin D receptor in human colon carcinomas. Int J Cancer. 2006;119:20982104.

65. Straza MW, Paliwal S, Kovi RC, Rajeshkumar B, Trenh P, Parker D, Whalen GF, Lyle S, Schiffer CA, Grossman SR. Therapeutic targeting of C-terminal binding protein in human cancer. Cell Cycle. 2010;9:3740-3750.

66. Puca R, Nardinocchi L, D’Orazi G. Regulation of vascular endothelial growth factor expression by homeodomaininteracting protein kinase-2. J Exp Clin. Cancer Res 2008;27:22.

67. Jiang Q, He M, Ma MT, Wu HZ, Yu ZJ, Guan S, Jiang LY, Wang Y, Zheng DD, Jin F, Wei MJ. MicroRNA-148a inhibits breast cancer migration and invasion by directly targeting WNT-1. Oncol Rep. 2015.

68. Bian Q, Liu P, Gu J, Song B. Tubeimoside-1 inhibits the growth and invasion of colorectal cancer cells through the Wnt/beta-catenin signaling pathway. Int J Clin Exp Pathol. 2015;8:12517-12524.

69. Ma X, Liu JX. Eafs control erythroid cell fate by regulating c-myb expression through Wnt signaling. PLoS One. 2013;8:e64576.

70. Liang J, Liu X, Xue H, Qiu B, Wei B, Sun K. MicroRNA103 a inhibits gastric cancer cell proliferation, migration and invasion by targeting c-Myb. Cell Prolif. 2015;48:78-85.

71. Yu L, Ding GF, He C, Sun L, Jiang Y, Zhu L. MicroRNA-424 is down-regulated in hepatocellular carcinoma and suppresses cell migration and invasion through c-Myb. PLoS One. 2014;9:e91661.

72. Kanei-Ishii C, Ninomiya-Tsuji J, Tanikawa J, Nomura T, Ishitani T, Kishida S, Kokura K, Kurahashi T, IchikawaIwata E, Kim Y, Matsumoto K, Ishii S. Wnt-1 signal induces phosphorylation and degradation of c-Myb protein via TAK1, HIPK2, and NLK. Genes Dev. 2004;18:816829.

73. Kanei-Ishii C, Nomura $T$, Takagi $T$, Watanabe $N$, Nakayama KI, Ishii S. Fbxw7 acts as an E3 ubiquitin ligase that targets c-Myb for nemo-like kinase (NLK)-induced degradation. J Biol Chem. 2008;283:30540-30548.

74. Bon G, Di Carlo SE, Folgiero V, Avetrani P, Lazzari C, D’Orazi G, Brizzi MF, Sacchi A, Soddu S, Blandino G, Mottolese M, Falcioni R. Negative regulation of beta4 integrin transcription by homeodomain-interacting protein kinase 2 and p53 impairs tumor progression. Cancer Res. 
2009;69:5978-5986.

75. Garufi A, Pistritto G, Ceci C, Di Renzo L, Santarelli R, Faggioni A, Cirone M, D’Orazi G. Targeting COX-2/ PGE(2) pathway in HIPK2 knockdown cancer cells: impact on dendritic cell maturation. PLoS One. 2012;7:e48342.

76. Eberhart CE, Coffey RJ, Radhika A, Giardiello FM, Ferrenbach S, DuBois RN. Up-regulation of cyclooxygenase 2 gene expression in human colorectal adenomas and adenocarcinomas. Gastroenterology. 1994;107:1183-1188.

77. Saukkonen K, Rintahaka J, Sivula A, Buskens CJ, Van Rees BP, Rio MC, Haglund C, Van Lanschot JJ, Offerhaus GJ, Ristimaki A. Cyclooxygenase-2 and gastric carcinogenesis. APMIS. 2003;111:915-925.

78. Dubois RN, Abramson SB, Crofford L, Gupta RA, Simon LS, Van De Putte LB, Lipsky PE. Cyclooxygenase in biology and disease. FASEB J. 1998;12:1063-1073.

79. Nodale C, Sheffer M, Jacob-Hirsch J, Folgiero V, Falcioni R, Aiello A, Garufi A, Rechavi G, Givol D, D’Orazi G. HIPK2 downregulates vimentin and inhibits breast cancer cell invasion. Cancer Biol Ther. 2012;13:198-205.

80. Hofmann TG, Jaffray E, Stollberg N, Hay RT, Will H. Regulation of homeodomain-interacting protein kinase 2 (HIPK2) effector function through dynamic small ubiquitinrelated modifier-1 (SUMO-1) modification. J Biol Chem. 2005;280:29224-29232.

81. Chen R, Chen S, Liao J, Chen X, Xu X. MiR-145 facilitates proliferation and migration of endothelial progenitor cells and recanalization of arterial thrombosis in cerebral infarction mice via JNK signal pathway. Int J Clin Exp Pathol. 2015;8:13770-13776.

82. Hao W, Wang S, Zhou Z. Tubeimoside-1 (TBMS1) inhibits lung cancer cell growth and induces cells apoptosis through activation of MAPK-JNK pathway. Int J Clin Exp Pathol. 2015;8:12075-12083.

83. Banerjee K, Basu S, Das S, Sinha A, Biswas MK, Choudhuri SK. Induction of intrinsic and extrinsic apoptosis through oxidative stress in drug resistant cancer by a newly synthesized Schiff base copper chelate. Free Radic Res. 2016:1-55.

84. Puca R, Nardinocchi L, Pistritto G, D’Orazi G. Overexpression of HIPK2 circumvents the blockade of apoptosis in chemoresistant ovarian cancer cells. Gynecol Oncol. 2008;109:403-410.

85. Lin J, Zhang Q, Lu Y, Xue W, Xu Y, Zhu Y, Hu X. Downregulation of HIPK2 increases resistance of bladder cancer cell to cisplatin by regulating Wip1. PLoS One. 2014;9:e98418.
86. Gabriella D, Cinzia R, Silvia S.Updates on HIPK2: a resourceful oncosuppressor for clearing cancer. J Exp Clin Cancer Res. 2012; 31:63.

87. Lazzari C, Prodosmo A, Siepi F, Rinaldo C, Galli F, Gentileschi M, Bartolazzi A, Costanzo A, Sacchi A, Guerrini L, Soddu S. HIPK2 phosphorylates DeltaNp63alpha and promotes its degradation in response to DNA damage. Oncogene. 2011;30:4802-4813.

88. Mao JH, Wu D, Kim IJ, Kang HC, Wei G, Climent J, Kumar A, Pelorosso FG, DelRosario R, Huang EJ, Balmain A. Hipk 2 cooperates with p53 to suppress gamma-ray radiation-induced mouse thymic lymphoma. Oncogene. 2012;31:1176-1180.

89. Zhou L, Feng Y, Jin Y, Liu X, Sui H, Chai N, Chen X, Liu N, Ji Q, Wang Y, Li Q. Verbascoside promotes apoptosis by regulating HIPK2-p53 signaling in human colorectal cancer. BMC Cancer. 2014;14:747.

90. Nina R, Julia A, Ziv P,Tilman PVa,Thomas GH, Yosef S. The Tyrosine Kinase c-Abl Promotes Homeodomaininteracting Protein Kinase 2 (HIPK2) Accumulation and Activation in Response to DNA Damage. J Biol Chem. 2015.;290: 16478-88.

91. Wang SY, Iordanov M, Zhang Q. c-Jun NH2-terminal kinase promotes apoptosis by down-regulating the transcriptional co-repressor CtBP. J Biol Chem. 2006;281:34810-34815.

92. Di SV, Rinaldo C, Sacchi A, Soddu S, D’Orazi G. Homeodomain-interacting protein kinase-2 activity and p53 phosphorylation are critical events for cisplatin-mediated apoptosis. Exp Cell Res. 2004;293:311-320.

93. Alessia G, Valentina U, Francesca M, Valerio D, Silvia B, Fabiola M, Gianluca B, Gabriella D. The beneficial effect of Zinc(II) on low-dose chemotherapeutic sensitivity involves p53 activation in wild-type p53-carrying colorectal cancer cells. J Exp Clin Cancer Res.2015;34: 87.

94. Margalit O, Simon AJ, Yakubov E, Puca R, Yosepovich A, Avivi C, Jacob-Hirsch J, Gelernter I, Harmelin A, Barshack I, Rechavi G, D’Orazi G, Givol D, Amariglio N. Zinc supplementation augments in vivo antitumor effect of chemotherapy by restoring p53 function. Int J Cancer. 2012;131:E562-568.

95. Wang L, Gao S, Jiang W, Luo C, Xu M, Bohlin L, Rosendahl M, Huang W. Antioxidative dietary compounds modulate gene expression associated with apoptosis, DNA repair, inhibition of cell proliferation and migration. Int $\mathrm{J}$ Mol Sci. 2014;15: 16226-16245. 